\title{
An insight into the removal of fluoroquinolones in activated sludge process: Sorption and biodegradation characteristics
}

\author{
Lu Wang, Zhimin Qiang, Yangang Li, Weiwei Ben* \\ Key Laboratory of Drinking Water Science and Technology, Research Center for Eco-Environmental Sciences, Chinese Academy of Sciences, \\ Beijing 100085, China
}

\section{A R T I C L E I N F O}

Article history:

Received 28 July 2016

Revised 21 September 2016

Accepted 8 October 2016

Available online 1 November 2016

Keywords:

Fluoroquinolones

Sorption

Biodegradation

Activated sludge

\begin{abstract}
A B S T R A C T
The detailed sorption steps and biodegradation characteristics of fluoroquinolones (FQs) including ciprofloxacin, enrofloxacin, lomefloxacin, norfloxacin, and ofloxacin were investigated through batch experiments. The results indicate that $F Q s$ at a total concentration of $500 \mu \mathrm{g} / \mathrm{L}$ caused little inhibition of sludge bioactivity. Sorption was the primary removal pathway of FQs in the activated sludge process, followed by biodegradation, while hydrolysis and volatilization were negligible. FQ sorption on activated sludge was a reversible process governed by surface reaction. Henry and Freundlich models could describe the FQ sorption isotherms well in the concentration range of 100-300 $\mu \mathrm{g} / \mathrm{L}$. Thermodynamic parameters revealed that FQ sorption on activated sludge is spontaneous, exothermic, and enthalpy-driven. Hydrophobicity-independent mechanisms determined the FQ sorption affinity with activated sludge. The zwitterion of FQs had the strongest sorption affinity, followed by cation and anion, and aerobic condition facilitated FQ sorption. FQs were slowly biodegradable, with long half-lives (>100 hr). FQ biodegradation was enhanced with increasing temperature and under aerobic condition, and thus was possibly achieved through co-metabolism during nitrification. This study provides an insight into the removal kinetics and mechanism of FQs in the activated sludge process, but also helps assess the environmental risks of FQs resulting from sludge disposal.

(c) 2016 The Research Center for Eco-Environmental Sciences, Chinese Academy of Sciences.
\end{abstract} Published by Elsevier B.V.

\section{Introduction}

Fluoroquinolones (FQs) are a class of broad-spectrum antibiotics with currently increasing use in human medical care and animal husbandry. Wastewater and solid waste originating from residential areas, hospitals, pharmaceutical manufacturers, livestock farms, and aquaculture facilities constitute the main sources of FQ contamination (Sukul and Spiteller, 2007; Lin et al., 2008). FQs are released into the natural environment along with wastewater discharge and waste disposal, and transport across multiple environmental media via various interactions, e.g., runoff, percolation, partitioning, and bioaccumulation (Van Doorslaer et al., 2014). Therefore, residual FQs have been frequently detected in aqueous matrices, soils, sediments, and biota (Gothwal and Shashidhar, 2015). Although their environmental concentrations are very low, usually at ng/L to $\mu \mathrm{g} / \mathrm{L}$ in water phases and $\mathrm{ng} / \mathrm{kg}$ to $\mathrm{mg} / \mathrm{kg}$ in solid phases, FQs have still attracted increasing attention because of their potential ecological risks arising from the selective formation of antibiotic-resistant bacteria over the long term (Van Doorslaer et al., 2014; Gothwal and Shashidhar, 2015).

\footnotetext{
* Corresponding author. E-mail: wwben@rcees.ac.cn (Weiwei Ben).
} 
FQs originating from multiple sources are usually discharged with sewage into wastewater treatment plants (WWTPs), which are considered to be the last barrier to minimize FQ release to the environment. Hence, the behavior of FQs in WWTPs deserves great concern. The occurrence and fate of FQs in WWTPs have been investigated through field sampling (Verlicchi et al., 2012; Yuan et al., 2015). Mass balance has also been performed to determine FQ removal efficiencies and potential removal pathways in WWTPs (Golet et al., 2002; Lindberg et al., 2006). Furthermore, the effects of operational strategies, e.g., sludge retention time (SRT), hydraulic retention time (HRT), and redox conditions, have also been evaluated by comparing the removal of FQs in WWTPs with varying designs and operations (Batt et al., 2007). Despite the well-known advantages, there are some difficulties in performing and controlling field investigations in WWTPs. For instance, the contributions of sorption and biodegradation to the overall removal of FQs may be overrated or underrated due to the fluctuations of sewage flow and excess sludge discharge. The solid-water sorption coefficient obtained by single-point calculation rather than sorption isotherms may not represent the FQs' sorption affinity appropriately at other concentrations (Stevens-Garmon et al., 2011).

To overcome the uncertainties of field sampling, wellcontrolled lab-scale reactors have been employed to evaluate the removal of FQs in the activated sludge process, and clarify the contributions and characteristics of different removal pathways, e.g., sorption and biodegradation (Wu et al., 2009; Dorival-Garcia et al., 2013). To date, most studies concerning FQ sorption on activated sludge have focused on equilibrium time, isotherms, and effects of operational conditions (e.g., concentrations of FQs and activated sludge, redox conditions, $\mathrm{pH}$, and co-existing ions) on FQ sorption (Zhou et al., 2013; Polesel et al., 2015); whereas the detailed sorption steps (e.g., film diffusion, intra-particle diffusion, and surface reaction) are rarely discussed. On the other hand, the role of biodegradation in the removal of FQs is not yet clear, and the limited studies on FQ biodegradation have yielded different results (Van Doorslaer et al., 2014).

Therefore, this study aimed to provide an insight into the removal of FQs in the activated sludge process, especially the roles and characteristics of FQ sorption and biodegradation. Ciprofloxacin (CIP), enrofloxacin (ENR), lomefloxacin (LOM), norfloxacin (NOR), and ofloxacin (OFL) were selected as target FQ antibiotics. Batch experiments were carried out to investigate the inhibition of sludge bioactivity by FQs, as well as the removal pathways and sorption isotherms of FQs in the activated sludge process. Moreover, different models were employed to clarify the rate-limiting step of FQ sorption on activated sludge, the effects of FQ speciation and sludge properties on sorption affinity, and the biodegradability of FQs under different redox conditions.

\section{Materials and methods}

\subsection{Chemicals}

The standards of caffeine (CAF) and LOM were obtained from Dr. Ehrenstorfer GmbH (Augsburg, Germany). NOR, OFL, CIP, and ENR were provided by Sigma-Aldrich (St. Louis, MO, USA). Caffeine- ${ }^{13} \mathrm{C}_{3}$ (Cerilliant, Round Rock, TX, USA) and ofloxacin- $\mathrm{D}_{3}$ (Witega, Berlin, Germany) were used as internal standards (ISs). The purity of all the standards was $\geq 98 \%$, and the major physicochemical properties of studied FQs and ISs are summarized in Appendix A. Table S1. HPLC-grade methanol and acetonitrile were purchased from Fisher Scientific (Geel, Belgium), and formic acid (purity > 99\%) from Dikma Technologies, Inc. (Lake Forest, GA, USA). $\mathrm{NaN}_{3}$ was obtained from Sigma-Aldrich (St. Louis, MO, USA). Other chemicals of at least analytical grade were purchased from Sinopharm Chemical Reagent Co., Ltd. (Beijing, China). The stock solutions of CAF (100 mg/L), FQs (100 mg/L each), and ISs (10 mg/L each) were used in batch experiments. Mill-Q water was produced by passing distilled water through a Milli-Q purification system (Advantage A10, Millipore, Billerica, MA, USA).

\subsection{Batch experiments}

Batch experiments were performed using activated sludge from a lab-scale sequencing batch reactor (SBR) fed with synthetic wastewater (Appendix A. Text S1). The activated sludge was repeatedly centrifuged and washed with Mill-Q water three times. After the last centrifugation, the remaining sludge was suspended in synthetic wastewater to reach a desired concentration of mixed liquor suspended solids (MLSS) $(3.8 \mathrm{~g} / \mathrm{L})$, which is referred to as treated sludge hereafter. The treated sludges originating from the aerobic and anoxic stages of the SBR were used in the experiments carried out under aerobic and anoxic conditions, respectively.

Three series of batch experiments were carried out using 250-mL Erlenmeyer flasks (working volume: $200 \mathrm{~mL}$ ), with experimental conditions shown in Table 1 . CAF and $\mathrm{NaN}_{3}$ were used to indicate the sludge bioactivity and inhibit the potential biodegradation of FQs in the activated sludge process, respectively. All the flasks were wrapped with aluminum foil to avoid possible photolysis. Comparisons of CAF biodegradation in Control A with that in Group I or II could indicate the inhibition degree of FQs or $\mathrm{NaN}_{3}$ on sludge bioactivity, respectively. The potential removal pathways of $\mathrm{FQs}$ in the activated sludge process include hydrolysis, volatilization, sorption, and biodegradation (Kummerer, 2009). All four pathways could simultaneously occur in Group IV, while biodegradation was excluded in Group III with the addition of $\mathrm{NaN}_{3}$. In Control B, only hydrolysis and volatilization accounted for the possible removal of FQs.

FQ or CAF stock solution was spiked into the flask to achieve the desired initial concentration (Table 1). Aerobic and anoxic conditions were provided by magnetic stirring in open and sealed flasks, respectively. The dissolved oxygen (DO) concentrations under each condition were 3.0-4.0 and $<0.7 \mathrm{mg} / \mathrm{L}$, respectively. Temperature was controlled by a thermostatic water bath. Initial $\mathrm{pH}$ was adjusted by $\mathrm{HCl}$ and $\mathrm{NaOH}$ solutions. For Control A and Groups I-IV, slurry samples were taken from the flask via syringe at the following times: 5, 10, 20, 30, 40, $50 \mathrm{~min}$; and 1, 1.5, 2, 3, 4, 6, 8, 10, 12, 18, 24, $36,48,50 \mathrm{hr}$, respectively. For Control B, sampling times were 1, 2, 4, 6, 8, 10, 12, 24, 36, 48 hr. For Groups V and VI, samples were collected after $6 \mathrm{hr}$ of exposure. All experiments were performed in duplicate, and duplicate samples (2 $\mathrm{mL}$ each) were taken from each parallel experiment. 


\begin{tabular}{|c|c|c|c|c|c|c|c|c|}
\hline Series & Group & $\begin{array}{l}\text { Treated sludge } \\
(\mathrm{g} / \mathrm{L})\end{array}$ & $\begin{array}{l}\mathrm{CAF}^{\mathrm{b}} \\
(\mu \mathrm{g} / \mathrm{L})\end{array}$ & $\begin{array}{c}\mathrm{FQ}^{\mathrm{c}} \\
(\mu \mathrm{g} / \mathrm{L})\end{array}$ & $\begin{array}{l}\mathrm{NaN}_{3} \\
(\mathrm{~W} / \mathrm{V})^{\mathrm{f}}\end{array}$ & $\begin{array}{l}\text { Temp. } \\
\left({ }^{\circ} \mathrm{C}\right)\end{array}$ & Redox condition & Initial $\mathrm{pH}$ \\
\hline \multirow[t]{3}{*}{ Inhibition of bioactivity } & Control A & 3.8 & 100 & $-{ }^{\mathrm{d}}$ & - & 17 & Aerobic & 7.3 \\
\hline & I & 3.8 & 100 & 100 & - & 17 & Aerobic & 7.3 \\
\hline & II & 3.8 & 100 & 100 & $0.1 \%$ & 17 & Aerobic & 7.3 \\
\hline \multirow[t]{3}{*}{ Removal pathways } & Control B ${ }^{a}$ & - & - & 100 & - & $17,22,30$ & Aerobic, anoxic & 7.3 \\
\hline & III & 3.8 & - & 100 & $0.1 \%$ & $17,22,30$ & Aerobic, anoxic & 7.3 \\
\hline & IV & 3.8 & - & 100 & - & $17,22,30$ & Aerobic, anoxic & 7.3 \\
\hline \multirow[t]{2}{*}{ Sorption isotherms } & $\mathrm{V}$ & 3.8 & - & $100-300^{e}$ & $0.1 \%$ & $17,22,30$ & Aerobic, anoxic & 7.30 \\
\hline & VI & 3.8 & - & $100-300^{e}$ & $0.1 \%$ & 22 & Aerobic & $3.2-9.3^{g}$ \\
\hline \multicolumn{9}{|c|}{$\begin{array}{l}\text { CAF: caffeine; FQ: fluoroquinolone. } \\
\text { a Treated sludge was substituted by synthetic wastewater. } \\
\text { b CAF was used as the reference compound to indicate the sludge bioactivity. } \\
\text { c The numbers in this column refer to the concentration of each FQ studied. } \\
\text { d Without addition. } \\
\text { e } 100,150,200,250,300 \mu \mathrm{g} / \mathrm{L} \text {. } \\
\text { f The ratio of weight }\left(\mathrm{NaN}_{3}\right) \text { to volume (treated sludge). } \\
\text { g pH gradients: } 3.2,4.3,5.3,6.3,7.3,8.3,9.3 \text {. }\end{array}$} \\
\hline
\end{tabular}

\subsection{Models}

Sorption amount (q) refers to the amount of FQs sorbed by each gram of MLSS. Appendix A. Table S2 lists the models tested in this study. The detailed steps of FQ sorption on activated sludge were explored by comparing the fitting of sorption data to different kinetic models with different premises. Henry, Freundlich, and Langmuir models were tested for their ability to describe FQ sorption isotherms. Biodegradation kinetics of FQs and CAF were fitted using a biodegradation pseudo-first-order model since their concentrations were very low in comparison with the sludge concentration (Li and Zhang, 2010). The goodness of fit was assessed using the determination coefficient $\left(R^{2}\right)$ and Marquardt's percent standard deviation (MPSD).

\subsection{Analysis}

MLSS and mixed liquor volatile suspended solids were measured according to the Standard Methods (APHA et al., 2012). Hach methods were used to determine the concentrations of chemical oxygen demand (method 8000), total nitrogen (methods 10,071 and 10,072), ammonia (methods 10,023 and 10,031), and total phosphorus (methods 10,127 and 8190) with a DR6000 UV-Vis spectrophotometer and a DRB200 digestion device (Hach, Shanghai, China). DO concentration was monitored with a portable DO meter (WTW, Munich, Germany). After centrifugation at 10,000 r/min for $1 \mathrm{~min}$, the supernatant of the slurry sample was filtered through $0.22-\mu \mathrm{m}$ filters, and stored at $4^{\circ} \mathrm{C}$ before analysis. CAF and FQ concentrations in the water phase were analyzed using ultra high performance liquid chromatography tandem mass spectrometry (UPLC-MS/MS, Agilent), which was operated in the positive ionization multiple reaction monitoring (MRM) mode. The detailed operational parameters of UPLC-MS/MS are presented in Appendix A. Text S2. The method quantitation limits for NOR, OFL, CIP, LOM, ENR, and CAF were 0.08, $0.01,0.08,0.14,0.17$, and $0.29 \mu \mathrm{g} / \mathrm{L}$, respectively.

\section{Results and discussion}

\subsection{FQ inhibition on sludge bioactivity}

Fig. 1 shows the biodegradation of CAF in Control A and in Groups I and II. The CAF removal in Control A was with the same as that in Group I, indicating that the presence of FQs at a total concentration of $500 \mu \mathrm{g} / \mathrm{L}$ caused little inhibition of the sludge bioactivity. In other words, this result indicates that the majority of microorganisms existing in the activated sludge under aerobic condition were not influenced by FQs, despite the broad-spectrum of pathogenic bacteria targeted by FQs (Kummerer et al., 2000). The reduced antibacterial activity

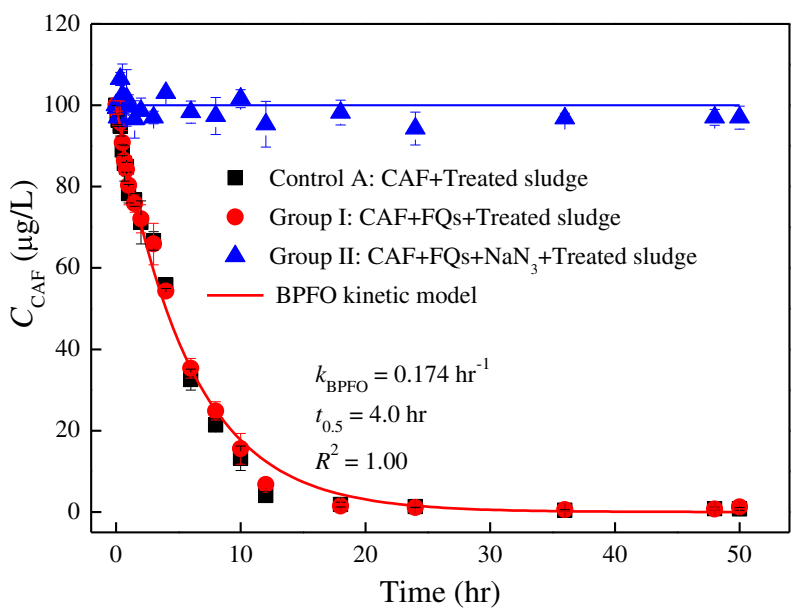

Fig. 1 - Inhibition of sludge bioactivity by FQs and $\mathrm{NaN}_{3}$. Experimental conditions: aerobic, temp. $=17^{\circ} \mathrm{C}, \mathrm{pH}=7.3$, $C_{\text {MLSS }}=3.8 \mathrm{~g} / \mathrm{L}, \mathrm{C}_{0, \mathrm{FQ}}=100 \mu \mathrm{g} / \mathrm{L}$ each (NOR, OFL, CIP, LOM, and ENR). BPFO: biodegradation pseudo-first-order. Error bars represent the standard deviation of four measurements. NOR: norfloxacin; OFL: ofloxacin; CIP: ciprofloxacin; LOM: lomefloxacin; ENR: enrofloxacin. 
of FQs in the activated sludge could probably be attributed to the inactivation of FQs by the antibiotic-sludge interactions (e.g., sorption) (Al-Ahmad et al., 1999). The rate constant $\left(k_{\mathrm{BPFO}}\right)$ and half-life $\left(t_{0.5}\right)$ of CAF biodegradation were $0.174 \mathrm{hr}^{-1}$ and $4.0 \mathrm{hr}$, respectively. In Group II, little removal of CAF was observed, implying that $0.1 \%(\mathrm{~W} / \mathrm{V}) \mathrm{NaN}_{3}$ could completely inhibit the sludge bioactivity, and the CAF sorption on activated sludge was negligible.

\subsection{FQ removal pathways in activated sludge process}

The removal of FQs is shown in Fig. 2 (NOR) and Appendix A. Fig. S1 (OFL, CIP, LOM, and ENR). The photolysis of FQs could be excluded because the experiments were conducted in the dark. Taking NOR as an example, Fig. 2 shows that its aqueous concentration remained nearly constant in Control B, indicating that its hydrolysis and volatilization could be ignored. The negligible volatilization of NOR was consistent with its very low Henry's constant (i.e., $8.70 \times 10^{-19} \mathrm{~atm} /\left(\mathrm{m}^{3} \cdot \mathrm{mol}\right)$ ), relatively large molecular weight, and the presence of several ionizable and polar moieties in its chemical structure (Appendix A. Table S1). Sorption was solely responsible for the removal of NOR in Group III, since the sludge bioactivity was completely inhibited by $\mathrm{NaN}_{3}$. However, the NOR removal in Groups III and IV exhibited an obvious difference after the initial sorption, demonstrating the occurrence of slow biodegradation in the activated sludge process. Similar results were obtained for other studied FQs (Appendix A. Fig. S1). In brief, sorption and biodegradation accounted for $78 \%-91 \%$ and $9 \%$ $22 \%$ of the overall removal of target FQs after $50 \mathrm{hr}$. It is seen that although FQs were biodegradable, the slow biodegradation rate rendered sorption the primary removal pathway of FQs in the activated sludge process.

\subsection{FQ sorption on activated sludge}

\subsubsection{Sorption process}

The sorption process of FQs on activated sludge consists of several consecutive steps including bulk mass transfer,

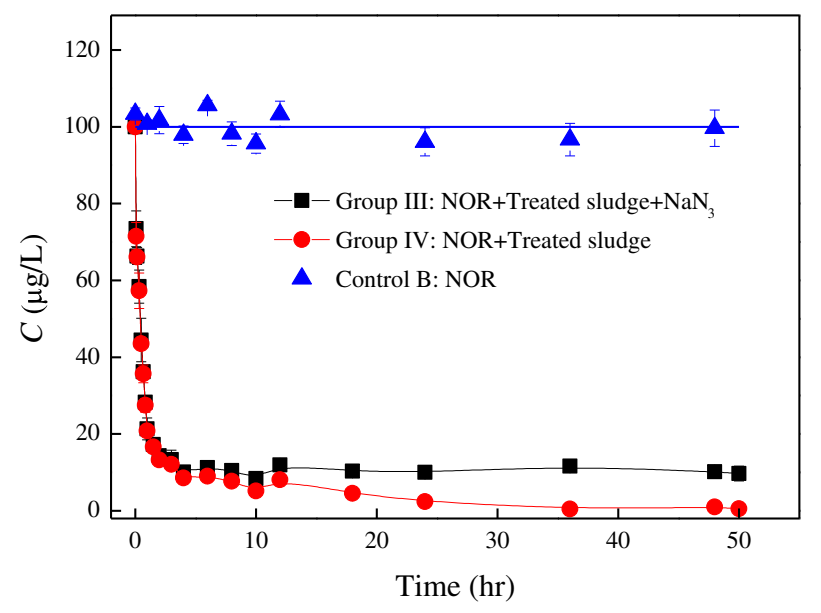

Fig. 2 - Removal of NOR in activated sludge process with time. Experimental conditions: aerobic, temp. $=17^{\circ} \mathrm{C}, \mathrm{pH}=7.3$, $\mathrm{C}_{\mathrm{MLSS}}=3.8 \mathrm{~g} / \mathrm{L}, \mathrm{C}_{0, \mathrm{NOR}}=100 \mu \mathrm{g} / \mathrm{L}$. Error bars represent the standard deviation of four measurements. liquid film diffusion, external surface reaction, intra-particle diffusion, and internal surface reaction. According to the boundary layer theory, the main resistance to liquid-phase mass transfer usually comes from the liquid film. Furthermore, because all experiments were carried out in well-stirred reaction systems, bulk mass transfer could not be the ratelimiting step. Thus, FQ sorption on activated sludge may be governed by the liquid film diffusion, intra-particle diffusion, or surface reaction.

Fig. 3a-d shows the fitting of NOR sorption data to different kinetic models. According to the $R^{2}$ and MPSD values, the pseudo-second-order and general-rate-law models provided better fits over the whole sorption process than the pseudofirst-order model (Fig. 3a), which was also observed in the kinetic model fitting of OFL, CIP, LOM, and ENR. The pseudo-second-order and general-rate-law models presume that the sorption process is governed by a sorption reaction on the sorbent surface (Liu and Shen, 2008; Sen Gupta and Bhattacharyya, 2011). Therefore, it is inferred that NOR sorption on activated sludge was primarily a surface reactioncontrolled process. The pseudo-second-order model parameters are summarized in Appendix A. Table S3. The rate constants $\left(k_{\mathrm{PSO}} \times q_{\mathrm{e}}\right)$ and initial sorption rates $\left(k_{\mathrm{PSO}} \times q_{\mathrm{e}}^{2}\right)$ reveal that the sorption rate of FQs generally followed the descending order: LOM $>$ ENR $>$ NOR $>$ CIP $>$ OFL. The equilibrium sorption amounts calculated by the pseudo-secondorder model ( $\left.q_{\mathrm{e}, \mathrm{PSO}}\right)$ were close to the experimental values $\left(q_{24-50 \mathrm{hr}}\right)$. Furthermore, intra-particle diffusion and film diffusion were also examined using intra-particle diffusion and film diffusion models, respectively. The intra-particle diffusion plot (Fig. 3b) could be divided into three linear portions (Stages 1, 2, and 3), corresponding to the rapid sorption, gradual sorption, and sorption equilibrium stages, respectively (Sarkar et al., 2003; Rengaraj et al., 2004). Because of the nonlinearity and nonzero intercept of the intra-particle diffusion plot, intra-particle diffusion was not the ratelimiting step (Weber and Morris, 1963; Ahmaruzzaman and Sharma, 2005). As shown in Appendix A. Table S4, more than $80 \%$ of $q_{\mathrm{e}}$ was achieved in Stage 1 ( $1 \mathrm{hr}$ ), and sorption equilibrium was reached at the end of Stage $2(4 \mathrm{hr})$. The film diffusion plot exhibited a similar trend (Fig. 3c), suggesting that film diffusion was not the rate-limiting step, either.

In addition, the fitness of other kinetic models was also examined. Results indicate that the standard-first-order, standard-second-order, standard- $n^{\text {th }}$-order, and Elovich models could only fit the NOR sorption data in the initial stage (Appendix A. Fig. S2), but failed to predict the sorption equilibrium, because all of them neglected the simultaneously occurring desorption process (Ho et al., 2000; Plazinski et al., 2009). Fig. $3 d$ shows that the reversible reaction model, which takes both sorption and desorption into account, could express the NOR sorption kinetics well over the whole sorption process. This indicates that the sorption reaction was reversible. Sorption and desorption will reach equilibrium after a certain contact time. However, when the environmental conditions (e.g., $\mathrm{pH}$, temperature, redox condition) and the operational strategies (e.g., HRT, SRT) are changed, this equilibrium may be disturbed, resulting in the release of FQs from sludge to the water phase. 

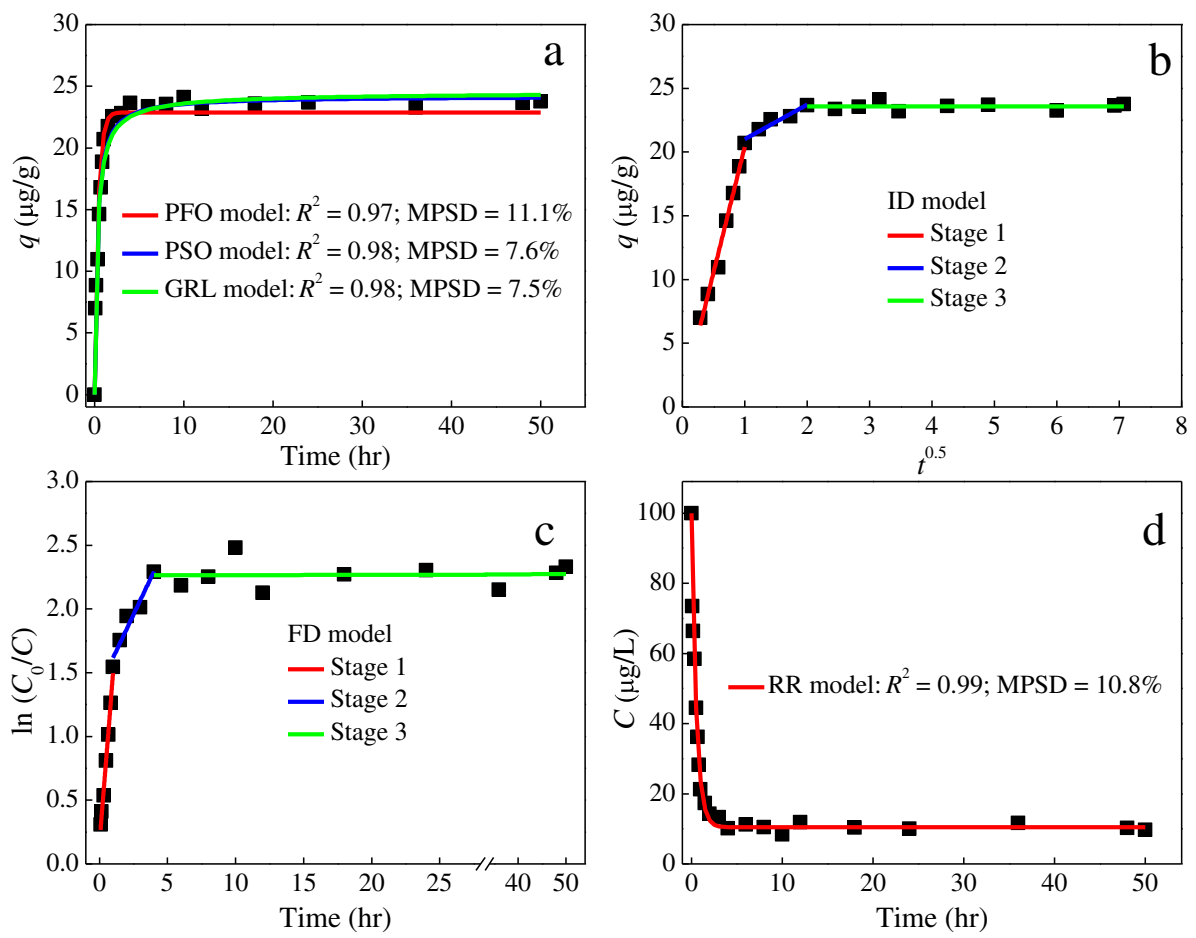

Fig. 3 - The fits of NOR sorption kinetics to PFO, PSO, GRL (a), ID (b), FD (c), and RR (d) models. Experimental conditions: aerobic, temp. $=17^{\circ} \mathrm{C}, \mathrm{pH}=7.3, \mathrm{C}_{\mathrm{MLSS}}=3.8 \mathrm{~g} / \mathrm{L}, \mathrm{C}_{0, \mathrm{NOR}}=100 \mu \mathrm{g} / \mathrm{L}, \mathrm{NaN}_{3}=0.1 \%(\mathrm{~W} / \mathrm{V})$. PFO: pseudo-first-order; PSO: pseudo-second-order; GRL: general-rate-law; ID: intra-particle diffusion; FD: film diffusion; RR: reversible reaction.

\subsubsection{Sorption isotherms and thermodynamics}

Both Henry and Freundlich models could fit the FQ isotherms data well, while the Langmuir model was not applicable (Table 2), which was in agreement with previous studies performed at low concentrations of FQs (Wu et al., 2009; Zhou et al., 2013; Polesel et al., 2015). However, other studies reported that the Langmuir model could fit the sorption isotherms of some FQs at relatively high concentrations (Liu et al., 2013). This discrepancy lies in the fact that the Langmuir model can be simplified to the Henry model at low sorbate concentrations when the reactive sites on the activated sludge are far from being saturated. As a result, the Henry

Table 2-Parameters of Henry, Freundlich, and Langmuir isotherm models under different temperature and redox conditions $\left(\mathrm{pH}=7.3, \mathrm{NaN}_{3}=0.1 \%(\mathrm{~W} / \mathrm{V})\right.$ ).

\begin{tabular}{|c|c|c|c|c|c|c|c|c|c|c|c|c|c|c|c|c|c|}
\hline \multirow[t]{3}{*}{ FQ } & \multirow{3}{*}{$\begin{array}{c}\text { Temp. } \\
\left({ }^{\circ} \mathrm{C}\right)\end{array}$} & \multicolumn{8}{|c|}{ Aerobic } & \multicolumn{8}{|c|}{ Anoxic } \\
\hline & & \multicolumn{2}{|c|}{ Henry } & \multicolumn{3}{|c|}{ Freundlich } & \multicolumn{3}{|c|}{ Langmuir } & \multicolumn{2}{|c|}{ Henry } & \multicolumn{3}{|c|}{ Freundlich } & \multicolumn{3}{|c|}{ Langmuir } \\
\hline & & $\mathrm{K}_{\mathrm{H}}{ }^{\mathrm{a}}$ & $R^{2}$ & $\mathrm{~K}_{\mathrm{F}}{ }^{\mathrm{a}}$ & $1 / n$ & $R^{2}$ & $K_{L}^{a}\left(\times 10^{-3}\right)$ & $q_{\max }^{a}$ & $R^{2}$ & $\mathrm{~K}_{\mathrm{H}}{ }^{\mathrm{a}}$ & $R^{2}$ & $\mathrm{~K}_{\mathrm{F}}^{\mathrm{a}}$ & $1 / n$ & $R^{2}$ & $K_{L}{ }^{a}\left(\times 10^{-3}\right)$ & $q_{\max }^{a}$ & $R^{2}$ \\
\hline \multirow[t]{3}{*}{ NOR } & 17 & 2.30 & 0.97 & 2.92 & 0.93 & 0.99 & 4.65 & 555.2 & 0.40 & 2.08 & 0.97 & 1.83 & 1.04 & 0.98 & 1.47 & 1426.4 & 0.61 \\
\hline & 22 & 1.96 & 0.97 & 2.49 & 0.93 & 0.99 & 4.22 & 517.0 & 0.37 & 1.75 & 0.99 & 2.30 & 0.92 & 1.00 & 3.88 & 507.1 & 0.55 \\
\hline & 30 & 1.59 & 0.97 & 1.91 & 0.95 & 0.98 & 2.28 & 745.3 & 0.33 & 1.40 & 0.98 & 1.16 & 1.05 & 0.99 & 0.13 & $11,005.3$ & 0.50 \\
\hline \multirow[t]{3}{*}{ OFL } & 17 & 0.85 & 0.97 & 1.08 & 0.94 & 0.97 & 1.44 & 638.9 & 0.54 & 0.76 & 0.97 & 0.61 & 1.05 & 0.98 & 0.46 & 1657.0 & 0.48 \\
\hline & 22 & 0.71 & 0.97 & 0.87 & 0.95 & 0.98 & 1.18 & 639.4 & 0.36 & 0.64 & 0.99 & 0.53 & 1.05 & 0.99 & 0.67 & 981.9 & 0.38 \\
\hline & 30 & 0.52 & 0.98 & 0.44 & 1.04 & 0.99 & 0.78 & 687.3 & 0.44 & 0.46 & 0.99 & 0.44 & 1.01 & 0.99 & 0.52 & 916.1 & 0.68 \\
\hline \multirow[t]{3}{*}{ CIP } & 17 & 1.85 & 0.97 & 2.01 & 0.98 & 0.98 & 1.26 & 1517.2 & 0.63 & 1.71 & 0.97 & 1.44 & 1.05 & 0.97 & 0.94 & 1844.2 & 0.42 \\
\hline & 22 & 1.53 & 0.97 & 1.68 & 0.97 & 0.98 & 1.69 & 939.2 & 0.51 & 1.43 & 0.97 & 1.94 & 0.91 & 0.98 & 3.46 & 461.1 & 0.57 \\
\hline & 30 & 1.09 & 0.97 & 1.02 & 1.02 & 0.98 & 0.80 & 1395.7 & 0.38 & 0.97 & 0.97 & 1.01 & 0.99 & 0.98 & 0.64 & 1553.4 & 0.42 \\
\hline \multirow[t]{3}{*}{ LOM } & 17 & 1.05 & 0.97 & 1.40 & 0.92 & 0.98 & 2.34 & 491.6 & 0.35 & 0.94 & 0.96 & 0.78 & 1.05 & 0.97 & 0.62 & 1542.9 & 0.49 \\
\hline & 22 & 0.87 & 0.97 & 0.83 & 1.01 & 0.98 & 0.49 & 1779.1 & 0.39 & 0.78 & 0.99 & 0.58 & 1.07 & 1.00 & 1.09 & 737.5 & 0.49 \\
\hline & 30 & 0.67 & 0.97 & 0.60 & 1.03 & 0.98 & 0.62 & 1124.2 & 0.43 & 0.58 & 0.99 & 0.83 & 0.92 & 0.99 & 1.54 & 422.8 & 0.54 \\
\hline \multirow[t]{3}{*}{ ENR } & 17 & 1.32 & 0.97 & 1.84 & 0.91 & 0.99 & 3.51 & 430.9 & 0.47 & 1.19 & 0.98 & 1.39 & 0.96 & 0.98 & 1.79 & 712.9 & 0.32 \\
\hline & 22 & 1.07 & 0.97 & 1.07 & 1.00 & 0.97 & 0.92 & 1200.5 & 0.70 & 0.97 & 0.97 & 1.00 & 1.00 & 0.98 & 1.20 & 854.4 & 0.60 \\
\hline & 30 & 0.77 & 0.96 & 1.20 & 0.89 & 0.98 & 2.72 & 329.2 & 0.31 & 0.70 & 0.98 & 0.87 & 0.95 & 0.99 & 0.56 & 1820.3 & 0.53 \\
\hline
\end{tabular}


constant $\left(\mathrm{K}_{\mathrm{H}}\right)$ could reflect the sorption affinity of FQs with activated sludge considering the trace levels of $F Q s$ present in the municipal sewage (ng/L to $\mu \mathrm{g} / \mathrm{L}$ ).

Based on the $K_{\mathrm{H}}$, thermodynamic parameters were calculated at different temperatures (Table 3). The negative $\Delta G^{\circ}$ and $\Delta H^{\circ}$ values manifest the spontaneous and exothermic nature of FQ sorption on activated sludge, and the negative $\Delta S^{\circ}$ values reveal the decreased degree of freedom of FQs after their combining with the sludge surface. Hence, FQ sorption on activated sludge was also an enthalpy-driven process.

\subsubsection{Impact factors of sorption affinity}

The sorption reaction could occur at multiple sites (e.g., non-polar, polar, negatively charged, and surficial Fe-Al) according to varying sludge compositions. The major sorption mechanisms include hydrophobic partitioning and hydrophobicity-independent mechanisms (e.g., electron donoracceptor complexes, cation exchange, cation bridging, and surface complexation) (MacKay and Vasudevan, 2012). The low octanol-water partitioning coefficients $\left(K_{\text {ow }}\right)$ of FQs (Appendix A. Table S1) indicate that hydrophobic partitioning is insignificant, as revealed by previous studies on the sorption of other ionogenic chemicals on activated sludge (Hyland et al., 2012; Sathyamoorthy and Ramsburg, 2013). Hence, the FQ sorption affinity with activated sludge is governed by hydrophobicityindependent mechanisms.

The experimental conditions (e.g., pH, redox condition) could impact the sorption affinity of FQs because the hydrophobicity-independent mechanisms are closely related to the speciation of FQs and sludge properties. As shown in Fig. 4a and Appendix A. Fig. S3, three charged species of FQs (i.e., anion, zwitterion, cation) existed in aqueous solution as a function of $\mathrm{pH}$, because they are ionogenic amphoteric compounds with two $\mathrm{pK}_{\mathrm{a}}$ values (Appendix A. Table S1). Hence, the overall $K_{H}$ was equal to a summation of the specific $K_{\mathrm{H}}$ multiplied by the distribution coefficient of each species.

$K_{\mathrm{H}}=K_{\mathrm{H}}^{-} \alpha^{-}+K_{\mathrm{H}}^{0} \alpha^{0}+K_{\mathrm{H}}^{+} \alpha^{+}$

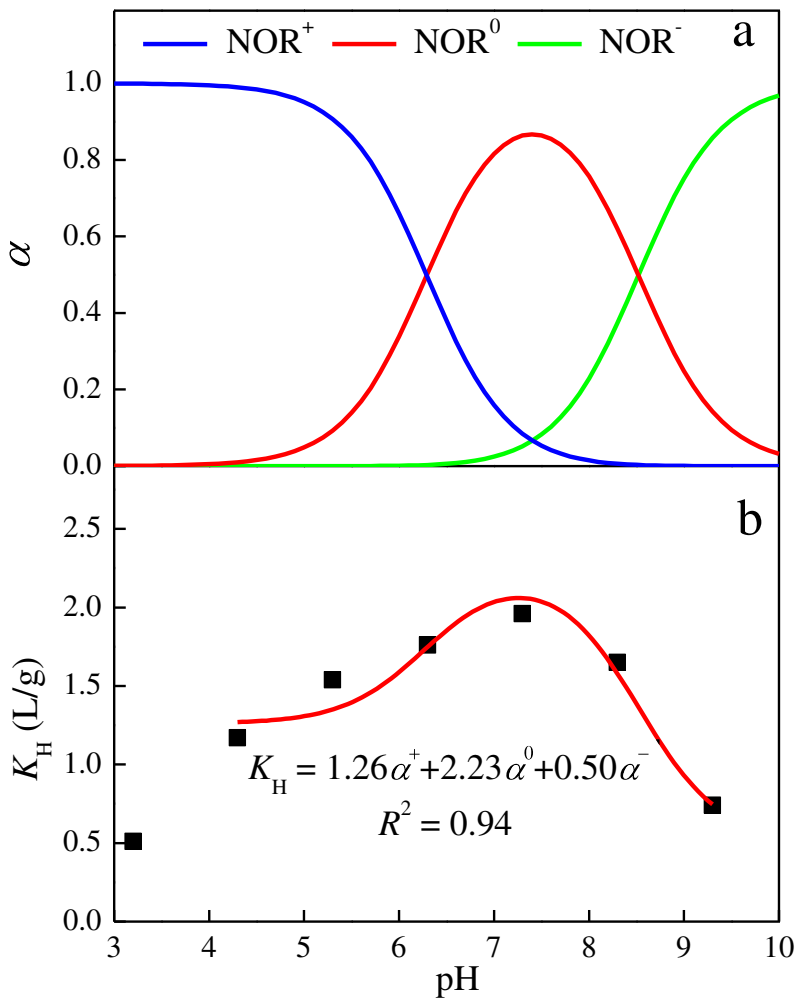

Fig. 4 - NOR speciation (a) and $\mathrm{K}_{\mathrm{H}}$ variation (b) with $\mathrm{pH}$. Experimental conditions: aerobic, temp. $=22^{\circ} \mathrm{C}, \mathrm{C}_{\mathrm{MLSS}}=3.8 \mathrm{~g} / \mathrm{L}$, $\mathrm{C}_{0, \mathrm{NOR}}=100 \mu \mathrm{g} / \mathrm{L}, \mathrm{NaN}_{3}=0.1 \%(\mathrm{~W} / \mathrm{V})$.

where $K_{\mathrm{H}}^{-}, K_{\mathrm{H}}^{0}$, and $\mathrm{K}_{\mathrm{H}}^{+}=$specific $\mathrm{K}_{\mathrm{H}}$ values of anion, zwitterion, and cation, respectively; and $\alpha^{-}, \alpha^{0}$, and $\alpha^{+}=$corresponding distribution coefficients. The overall $K_{\mathrm{H}}$ values could be fitted well with Eq. (1) in the $\mathrm{pH}$ range of $4.3-9.3$ (Fig. $4 \mathrm{~b}$ and Appendix A. Fig. S4). The specific $K_{\mathrm{H}}$ values of FQs (Appendix A. Table S5) indicate that zwitterion possessed the strongest sorption affinity, followed by cation and anion. The contributions of different species of FQs to the overall

Table 3 - Thermodynamic parameters for $\mathrm{FQ}$ sorption on activated sludge $\left(\mathrm{pH}=7.3, \mathrm{NaN}_{3}=0.1 \%(\mathrm{~W} / \mathrm{V})\right)$.

\begin{tabular}{|c|c|c|c|c|c|c|c|}
\hline \multirow[t]{2}{*}{$\mathrm{FQ}$} & \multirow[t]{2}{*}{ Temp. $\left({ }^{\circ} \mathrm{C}\right)$} & \multicolumn{3}{|c|}{ Aerobic } & \multicolumn{3}{|c|}{ Anoxic } \\
\hline & & $\Delta \mathrm{G}^{\circ}(\mathrm{kJ} / \mathrm{mol})$ & $\Delta H^{\circ}(\mathrm{kJ} / \mathrm{mol})$ & $\Delta \mathrm{S}^{\circ}(\mathrm{J} /(\mathrm{mol} \cdot \mathrm{K}))$ & $\Delta G^{\circ}(\mathrm{kJ} / \mathrm{mol})$ & $\Delta H^{\circ}(\mathrm{kJ} / \mathrm{mol})$ & $\Delta \mathrm{S}^{\circ}(\mathrm{J} /(\mathrm{mol} \cdot \mathrm{K}))$ \\
\hline \multirow[t]{3}{*}{ NOR } & 17 & -18.68 & -20.83 & -7.47 & -18.43 & -21.89 & -11.99 \\
\hline & 22 & -18.60 & & & -18.32 & & \\
\hline & 30 & -18.57 & & & -18.26 & & \\
\hline \multirow[t]{3}{*}{ OFL } & 17 & -16.28 & -28.30 & -41.39 & -15.99 & -28.23 & -42.09 \\
\hline & 22 & -16.11 & & & -15.85 & & \\
\hline & 30 & -15.75 & & & -15.45 & & \\
\hline \multirow[t]{3}{*}{ CIP } & 17 & -18.14 & -29.52 & -39.16 & -17.96 & -32.40 & -49.63 \\
\hline & 22 & -17.99 & & & -17.82 & & \\
\hline & 30 & -17.64 & & & -17.33 & & \\
\hline \multirow[t]{3}{*}{ LOM } & 17 & -16.77 & -24.80 & -27.72 & -16.53 & -27.14 & -36.60 \\
\hline & 22 & -16.61 & & & -16.33 & & \\
\hline & 30 & -16.41 & & & -16.05 & & \\
\hline \multirow[t]{3}{*}{ ENR } & 17 & -17.34 & -33.22 & -54.66 & -17.08 & -29.91 & -44.19 \\
\hline & 22 & -17.12 & & & -16.88 & & \\
\hline & 30 & -16.74 & & & -16.51 & & \\
\hline
\end{tabular}


sorption calculated by Eq. (1) show that the major contributor was the zwitterion (74\%-98\%) under typical pH conditions in WWTPs (6.5-7.5).

It should be pointed out that $\mathrm{K}_{\mathrm{H}}$ at $\mathrm{pH} 3.2$ was also examined. However, it was not used to fit Eq. (1) because pH 3.2 was close to the zero point of charge of activated sludge $\left(\mathrm{pH}_{\mathrm{ZPC}}=2.9 \pm 0.3\right)$ (Wang et al., 2000), at which point the surface charge begins to turn from negative to positive. Hence, the repulsion between the positively charged surface and cationic species significantly prevented FQ sorption on activated sludge at $\mathrm{pH}$ 3.2. The higher $\mathrm{K}_{\mathrm{H}}$ under aerobic condition than under anoxic condition (Table 2) indicates that aerobic condition facilitated FQ sorption. This could arise from the variation of sludge properties under different redox conditions, for example, anoxic condition could cause the reduction of ferric to ferrous ions and changes in the properties of extracellular polymeric substances (Delle Site, 2001; Zhu et al., 2015).

\subsection{FQ biodegradation in activated sludge process}

Previous studies on FQ biodegradation yielded different results. Li and Zhang (2010) reported that no biodegradation of FQs occurred in fresh-water sewage treatment systems, while Dorival-Garcia et al. (2013) demonstrated that biodegradation caused up to $60 \%$ of $\mathrm{FQ}$ removal in nitrifying activated sludge. Thus, this study attempted to gain an insight into FQ biodegradation in the activated sludge process. The biodegradation kinetics of FQs could be well expressed by the pseudo-first-order biodegradation model (Fig. 5a), and the related parameters are summarized in Appendix A. Table S6. Because the half-lives of FQs $\left(t_{0.5}\right)$ under aerobic and anoxic conditions were 104.3-267.6 and 517.3-1083.0 hr, respectively, the HRT was not long enough to achieve significant biodegradation in WWTPs. The specific biodegradation rate constants $\left(k_{\mathrm{BPFO}}\right.$,spe $)$ reveal that the FQs were slowly biodegradable. The contribution of biodegradation to the overall removal of FQs could also be evaluated by $k_{\text {BPFO,spe. For the }}$ SBR used in this study (Appendix A. Text S1), the removal efficiencies of $\mathrm{FQs}$ via biodegradation were calculated as $4 \%-5 \%$ (at $17{ }^{\circ} \mathrm{C}$ ), which were less by far than those via sorption $(77 \%-90 \%)$ as calculated according to $\mathrm{K}_{\mathrm{H}}$ (at $17{ }^{\circ} \mathrm{C}$ ). The temperature effect on FQ biodegradation was expressed by the Arrhenius equation (Fig. 5b), and the activation energies ranged from 14.41 to $20.30 \mathrm{~kJ} / \mathrm{mol}$ for the various FQs studied.

The $k_{\mathrm{BPFO}}$,spe values under different redox conditions (Appendix A. Table S6) reveal that aerobic condition favored FQ biodegradation. In this study, the microbial community remained nearly constant under the steady-state operating conditions, because different redox conditions were achieved cyclically in the same SBR. Thus, the difference in $k_{\mathrm{BPFO} \text {,spe }}$ could be attributed to the difference in microbial activities under aerobic and anoxic conditions. It is well-known that nitrification and denitrification occur under aerobic and anoxic conditions, respectively. Furthermore, the biodegradation of trace organic contaminants (TrOCs) is correlated strongly with both nitrifying bacteria (e.g., ammonia oxidizing bacteria) and ammonia monooxygenase (a catalyst in the nitrification process) (Falas et al., 2012; Dorival-Garcia et al., 2013),
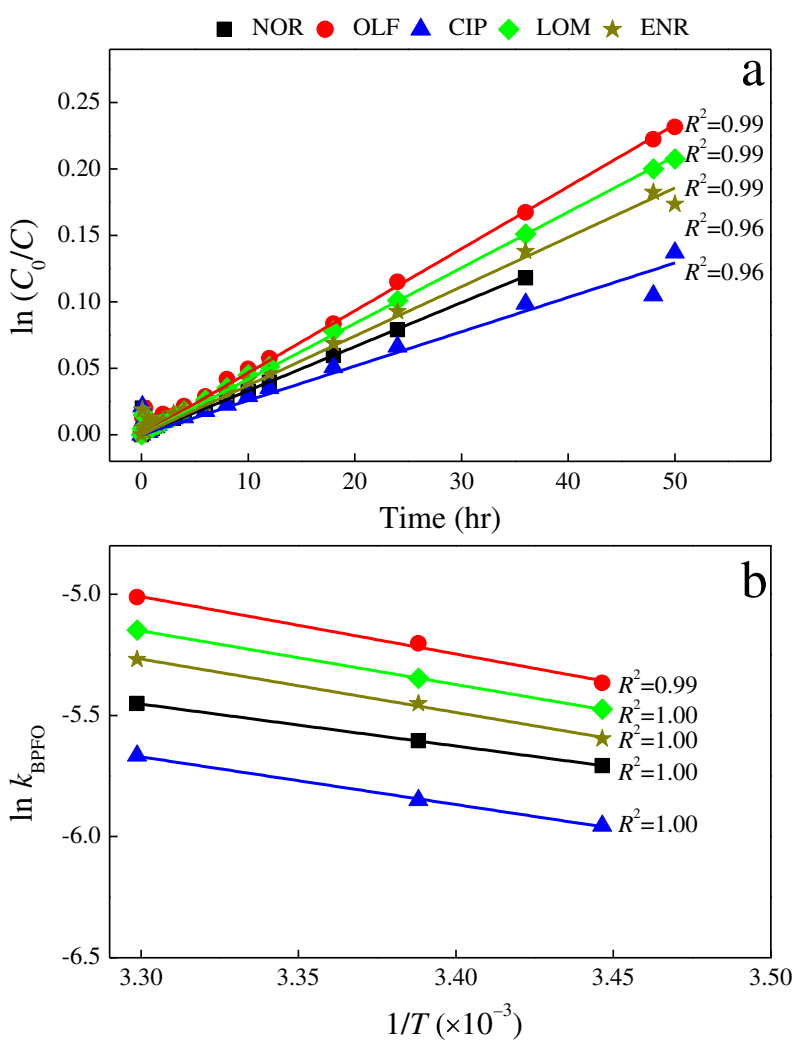

Fig. 5 - Biodegradation of FQs with time (a) and Arrhenius plot of $k_{\mathrm{BPFO}}$ as a function of temperature (T) (b). Experimental conditions: aerobic, temp. (a) $=17^{\circ} \mathrm{C}$, temp. (b) $=17,22$, and $30^{\circ} \mathrm{C}, \mathrm{pH}=7.3, \mathrm{C}_{\mathrm{MLSS}}=3.8 \mathrm{~g} / \mathrm{L}, \mathrm{C}_{0, \mathrm{FQ}}=100 \mu \mathrm{g} / \mathrm{L}$ each $(\mathrm{NOR}$, OFL, CIP, LOM, and ENR).

so co-metabolism tends to be the primary removal mechanism for TrOCs (Tran et al., 2013). Similarly, FQ biodegradation by activated sludge could also arise from co-metabolism in the nitrification process. In addition, the biodegradability of TrOCs depends strongly on their structures. TrOCs with highly branched or short hydrocarbon chains, halogen, sulfonate, methoxy, and nitro moieties are generally refractory to biodegradation (Hai et al., 2011). However, the piperazine ring of FQs, a hexa-heterocycle bearing two nitrogen atoms, could be attacked preferentially by enzymes, which supports the hypothesis that nitrification could improve the FQ biodegradation (Dorival-Garcia et al., 2013; Liu et al., 2013; Maia et al., 2014).

\subsection{Environmental implications}

Since the FQ sorption affinity with activated sludge is influenced by both FQ speciation and sludge properties, engineering design, and operational strategy (e.g., HRT, SRT) can influence FQ removal efficiencies in WWTPs. This study reveals that sorption is the primary removal pathway of FQs in the activated sludge process, while FQ biodegradation is much less important. Thus, sludge is the primary sink for 
FQs in WWTPs, and FQs may enter the natural environment mainly through sludge disposal (e.g., land application, landfill). In addition, this study also shows that FQ sorption on activated sludge is reversible. It is important to note that FQs sorbed on activated sludge can be desorbed when local conditions are changed, which facilitates FQ transportation from sludge to various environmental matrices. For example, the environmental conditions (e.g., pH, temperature, redox condition, the contents of organic matter and inorganic compounds) of soils are very different from those in WWTPs. Thus, if excess sludge is applied as fertilizer to agricultural land, FQs originally sorbed on sludge may become desorbed and transfer to soils. Consequently, more attention should be paid to the fate of FQs in the post-treatment processes of excess sludge. Considering that FQs are slowly biodegradable with long half-lives in the activated sludge process, sludge post-treatment (e.g., anaerobic digestion) may not achieve effective elimination of FQs (Golet et al., 2003; Lindberg et al., 2006). The structures of FQs contain benzene ring and amino groups, which are easily attacked by oxidants such as $\mathrm{O}_{3}$. Therefore, an in-situ sludge reduction process coupling biological treatment processes (e.g., A/A/O) with excess sludge ozonation (Qiang et al., 2015) could be a potential technology for FQ elimination.

\section{Conclusions}

This study investigated the detailed sorption steps and biodegradation characteristics of five typical fluoroquinolone antibiotics through batch experiments. Based on the experimental results, the following conclusions were obtained: (1) FQs at a total concentration of $500 \mu \mathrm{g} / \mathrm{L}$ caused little inhibition of sludge bioactivity as inferred from CAF biodegradation. (2) Sorption and biodegradation accounted for $78 \%$ $91 \%$ and $9 \%-22 \%$ of $\mathrm{FQ}$ removal after $50 \mathrm{hr}$, respectively, indicating that sorption was the primary removal pathway of FQs in the activated sludge process. (3) FQ sorption on activated sludge was a reversible process governed by surface reaction. Henry and Freundlich models could fit FQ sorption isotherms well in the concentration range of 100-300 $\mu \mathrm{g} / \mathrm{L}$. Thermodynamic parameters $\left(\Delta G^{\circ}, \Delta H^{\circ}\right.$, and $\left.\Delta S^{\circ}\right)$ showed that FQ sorption on activated sludge was a spontaneous, exothermic, and enthalpy-driven process. The zwitterion of FQs had the strongest sorption affinity with activated sludge, followed by the cation and anion. Aerobic condition facilitated FQ sorption in comparison with anoxic condition. (4) FQs were slowly biodegradable, with long half-lives (>100 hr), which resulted in insignificant biodegradation of FQs in WWTPs. FQ biodegradation was probably achieved through co-metabolism during the nitrification process. (5) Because excess sludge is a primary sink for FQs, its post-treatment and disposal need great attention concerning the environmental risks of residual FQs.

\section{Acknowledgments}

This study was financially supported by the National Natural Science Foundation (Nos. 21590814, 51525806).

\section{Appendix A. Supplementary data}

Supplementary data to this article can be found online at http://dx.doi.org/10.1016/j.jes.2016.10.006.

\section{R E F E R E N C E S}

Ahmaruzzaman, M., Sharma, D.K., 2005. Adsorption of phenols from wastewater. J. Colloid Interface Sci. 287 (1), 14-24.

Al-Ahmad, A., Daschner, F.D., Kummerer, K., 1999. Biodegradability of cefotiam, ciprofloxacin, meropenem, penicillin $\mathrm{G}$, and sulfamethoxazole and inhibition of waste water bacteria. Arch. Environ. Contam. Toxicol. 37 (2), 158-163.

APHA, AWWA, WEF, 2012. Standard Methods for the Examination of Water and Wastewater. 22nd ed American Public Health Association, Washington DC, USA.

Batt, A.L., Kim, S., Aga, D.S., 2007. Comparison of the occurrence of antibiotics in four full-scale wastewater treatment plants with varying designs and operations. Chemosphere 68 (3), 428-435.

Delle Site, A., 2001. Factors affecting sorption of organic compounds in natural sorbent/water systems and sorption coefficients for selected pollutants. A review. J. Phys. Chem. Ref. Data 30 (1), 187-439.

Dorival-Garcia, N., Zafra-Gomez, A., Navalon, A., Gonzalez-Lopez, J., Hontoria, E., Vilchez, J.L., 2013. Removal and degradation characteristics of quinolone antibiotics in laboratory-scale activated sludge reactors under aerobic, nitrifying and anoxic conditions. J. Environ. Manage. 120, 75-83.

Falas, P., Andersen, H.R., Ledin, A., Jansen, J.L., 2012. Impact of solid retention time and nitrification capacity on the ability of activated sludge to remove pharmaceuticals. Environ. Technol. 33 (8), 865-872.

Golet, E.M., Alder, A.C., Giger, W., 2002. Environmental exposure and risk assessment of fluoroquinolone antibacterial agents in wastewater and river water of the Glatt Valley Watershed, Switzerland. Environ. Sci. Technol. 36 (17), 3645-3651.

Golet, E.M., Xifra, I., Siegrist, H., Alder, A.C., Giger, W., 2003. Environmental exposure assessment of fluoroquinolone antibacterial agents from sewage to soil. Environ. Sci. Technol. 37 (15), 3243-3249.

Gothwal, R., Shashidhar, T., 2015. Antibiotic pollution in the environment: a review. Clean: Soil Air Water 43 (4), 479-489.

Hai, F.I., Tadkaew, N., McDonald, J.A., Khan, S.J., Nghiem, L.D., 2011. Is halogen content the most important factor in the removal of halogenated trace organics by MBR treatment? Bioresour. Technol. 102 (10), 6299-6303.

Ho, Y.S., Ng, J.C.Y., Mckay, G., 2000. Kinetics of pollutant sorption by biosorbents: review. Sep. Purif. Methods 29 (2), 189-232.

Hyland, K.C., Dickenson, E.R.V., Drewes, J.E., Higgins, C.P., 2012. Sorption of ionized and neutral emerging trace organic compounds onto activated sludge from different wastewater treatment configurations. Water Res. 46 (6), 1958-1968.

Kummerer, K., 2009. Antibiotics in the aquatic environment-a review-part I. Chemosphere 75 (4), 417-434.

Kummerer, K., Al-Ahmad, A., Mersch-Sundermann, V., 2000. Biodegradability of some antibiotics, elimination of the genotoxicity and affection of wastewater bacteria in a simple test. Chemosphere 40 (7), 701-710.

Li, B., Zhang, T., 2010. Biodegradation and adsorption of antibiotics in the activated sludge process. Environ. Sci. Technol. 44 (9), 3468-3473.

Lin, A.Y.C., Yu, T.H., Lin, C.F., 2008. Pharmaceutical contamination in residential, industrial, and agricultural waste streams: risk 
to aqueous environments in Taiwan. Chemosphere 74 (1), 131-141.

Lindberg, R.H., Olofsson, U., Rendahl, P., Johansson, M.I., Tysklind, M., Andersson, B.A.V., 2006. Behavior of fluoroquinolones and trimethoprim during mechanical, chemical, and active sludge treatment of sewage water and digestion of sludge. Environ. Sci. Technol. 40 (3), 1042-1048.

Liu, Y., Shen, L., 2008. A general rate law equation for biosorption. Biochem. Eng. J. 38 (3), 390-394.

Liu, Z.G., Sun, P.Z., Pavlostathis, S.G., Zhou, X.F., Zhang, Y.L., 2013. Adsorption, inhibition, and biotransformation of ciprofloxacin under aerobic conditions. Bioresour. Technol. 144, 644-651.

MacKay, A.A., Vasudevan, D., 2012. Polyfunctional ionogenic compound sorption: challenges and new approaches to advance predictive models. Environ. Sci. Technol. 46 (17), 9209-9223.

Maia, A.S., Ribeiro, A.R., Amorim, C.L., Barreiro, J.C., Cass, Q.B., Castro, P.M., Tiritan, M.E., 2014. Degradation of fluoroquinolone antibiotics and identification of metabolites/transformation products by liquid chromatography-tandem mass spectrometry. J. Chromatogr. A 1333, 87-98.

Plazinski, W., Rudzinski, W., Plazinska, A., 2009. Theoretical models of sorption kinetics including a surface reaction mechanism: a review. Adv. Colloid Interf. Sci. 152 (1-2), 2-13.

Polesel, F., Lehnberg, K., Dott, W., Trapp, S., Thomas, K.V., Plosz, B.G., 2015. Factors influencing sorption of ciprofloxacin onto activated sludge: experimental assessment and modelling implications. Chemosphere 119, 105-111.

Qiang, Z.M., Wang, L., Dong, H.Y., Qu, J.H., 2015. Operation performance of an A/A/O process coupled with excess sludge ozonation and phosphorus recovery: a pilot-scale study. Chem. Eng. J. 268, 162-169.

Rengaraj, S., Kim, Y., Joo, C.K., Yi, J., 2004. Removal of copper from aqueous solution by aminated and protonated mesoporous aluminas: kinetics and equilibrium. J. Colloid Interface Sci. 273 (1), 14-21.

Sarkar, M., Acharya, P.K., Bhattacharya, B., 2003. Modeling the adsorption kinetics of some priority organic pollutants in water from diffusion and activation energy parameters. J. Colloid Interface Sci. 266 (1), 28-32.

Sathyamoorthy, S., Ramsburg, C.A., 2013. Assessment of quantitative structural property relationships for prediction of pharmaceutical sorption during biological wastewater treatment. Chemosphere 92 (6), 639-646.
Sen Gupta, S., Bhattacharyya, K.G., 2011. Kinetics of adsorption of metal ions on inorganic materials: a review. Adv. Colloid Interf. Sci. 162 (1-2), 39-58.

Stevens-Garmon, J., Drewes, J.E., Khan, S.J., McDonald, J.A., Dickenson, E.R.V., 2011. Sorption of emerging trace organic compounds onto wastewater sludge solids. Water Res. 45 (11), 3417-3426.

Sukul, P., Spiteller, M., 2007. Fluoroquinolone antibiotics in the environment. Rev. Environ. Contam. Toxicol. 191, 131-162.

Tran, N.H., Urase, T., Ngo, H.H., Hu, J.Y., Ong, S.L., 2013. Insight into metabolic and cometabolic activities of autotrophic and heterotrophic microorganisms in the biodegradation of emerging trace organic contaminants. Bioresour. Technol. 146, 721-731.

Van Doorslaer, X., Dewulf, J., Van Langenhove, H., Demeestere, K., 2014. Fluoroquinolone antibiotics: an emerging class of environmental micropollutants. Sci. Total Environ. 500, 250-269.

Verlicchi, P., Al Aukidy, M., Zambello, E., 2012. Occurrence of pharmaceutical compounds in urban wastewater: removal, mass load and environmental risk after a secondary treatment-a review. Sci. Total Environ. 429, 123-155.

Wang, J.M., Huang, C.P., Allen, H.E., 2000. Surface physical-chemical characteristics of sludge particulates. Water Environ. Res. 72 (5), 545-553.

Weber, W.J., Morris, J.C., 1963. Kinetics of adsorption on carbon solution. J. Sanit. Eng. Div. Am. Soc. Civ. Eng. 89 (2), 31-59.

Wu, C.X., Spongberg, A.L., Witter, J.D., 2009. Sorption and biodegradation of selected antibiotics in biosolids. J. Environ. Sci. Health, Part A: Toxic/Hazard. Subst. Environ. Eng. 44 (5), 454-461.

Yuan, X.J., Qiang, Z.M., Ben, W.W., Zhu, B., Qu, J.H., 2015. Distribution, mass load and environmental impact of multiple-class pharmaceuticals in conventional and upgraded municipal wastewater treatment plants in East China. Environ. Sci. Processes Impacts 17 (3), 596-605.

Zhou, X.F., Zhang, Y.L., Shi, L., Chen, J.B., Qiang, Z.M., Zhang, T.C., 2013. Partitioning of fluoroquinolones on wastewater sludge. Clean: Soil Air Water 41 (8), 820-827.

Zhu, L., Zhou, J.H., Lv, M.L., Yu, H.T., Zhao, H., Xu, X.Y., 2015. Specific component comparison of extracellular polymeric substances (EPS) in flocs and granular sludge using EEM and SDS-PAGE. Chemosphere 121, 26-32. 